\title{
Factors associated with blood pressure control among patients attending the outpatient clinic of a South African district hospital
}

\author{
MM Batubenga ${ }^{1}$ MD, MMed (Fam Med) UP
}

OB Omole 2 MBBS, DA, MCFP (SA), MMed (Fam Med) MEDUNSA

\author{
MC Bondo 3 MD, MMed (Fam Med) UP \\ ${ }^{1}$ Specialist Family Physician, Department of Family Medicine, University of Pretoria, Pretoria, South Africa \\ ${ }^{2} \mathrm{Head}$ of Clinical unit and Senior Lecturer, Department of Family Medicine, University of the Witwatersrand, \\ Johannesburg, South Africa \\ ${ }^{3}$ Head of Clinical unit and Senior Lecturer, Department of Family Medicine, University of Pretoria, Pretoria, South Africa
}

Correspondence to: Dr. OB Omole, Department of Family Medicine (10th Floor, Medical School), University of the Witwatersrand, 7 York Street, Parktown, Johannesburg, South Africa. Email: alagbaomole@gmail.com

\begin{abstract}
Objective To determine the prevalence and factors associated with blood pressure (BP) control. Methods In a cross-sectional study involving 251 consecutively-sampled patients, a semi-structured questionnaire collected information on socio-demography, co-morbidities, hypertension treatments and BP control. Data analysis included descriptive statistics and logistic regression.

Results Most participants were: on treatment for $>5$ years $(60.6 \%)$; on three or more drugs $(93.6 \%)$; treated according to guidelines (77\%); and reported not missing medications in the last week (86.5\%). BP control was achieved in only $31.5 \%$ and $16.7 \%$ of participants at the current and last visits, respectively. In multivariate regression analysis, a history of myocardial infarction (odd ratio $[\mathrm{OR}]=0.41 ; P=0.04$ ) and being divorced/widowed $(\mathrm{OR}=3.1 ; P=0.01)$ predicted poor $\mathrm{BP}$ control.

Conclusion This study confirms the prevalent sub-optimal control of BP and suggests the need for further studies to examine the relationship between marital support, critical medical events and BP control.
\end{abstract}

Keywords: social relationship, hypertension control, experiences factors 


\section{Background}

Hypertension remains the commonest chronic disease and according to the World Health Organization, affects over 1 billion people worldwide in 2008 or $40 \%$ of adults over the age of 25 years. [1] The same report also indicates that hypertension is most prevalent in the African region, where about $46 \%$ of adults above the age of 25 years are affected. In South Africa, not only is hypertension the commonest diagnosis and reason for clinic attendance among adults attending primary care, [2] it is also the $2^{\text {nd }}$ leading cause of death 2 [3]. About $25 \%$ of the general adult population are reported to be affected by hypertension $[4,5]$ but prevalence of up to $77.3 \%$ have been reported among people older than 50 years of age. [2]

Hypertension is a major risk factor for cardiovascular disease (CVD) and increases the risk of morbidity and mortality from stroke, coronary heart disease, heart failure and renal failure. [6] It accounts for at least $45 \%$ to $51 \%$ of the global deaths from ischemic heart diseases and strokes. [1] Most of these deaths occur in developing countries like South Africa, where hypertension is highly prevalent, complications tend to be severe, costs of adequate treatments are less affordable and the healthcare system ill-equipped to adequately respond to the emerging CVD epidemic. [7, 8] Studies conducted in South Africa, including a recent one in one of three community health centres $(\mathrm{CHC})$ that refer to the district hospital under investigation, have found that hypertension control is suboptimal. [4, 5, 9, 10, 11] Achieving optimal hypertension control is therefore not only a clinical and public health priority for CVD burden reduction in South Africa as a country but for our local health district also.

Studies conducted elsewhere have found that hypertension control is influenced by factors such as: patients' demographic and socio-economic characteristics, affordability and access to healthcare services, patients' adherence and tolerance of treatments, effectiveness of treatment and clinicians' adherence to evidence-based guidelines. [2, 12] However, the contribution of each factor varies depending on the study 
context, making it challenging to apply these findings across all socio-economic and healthcare contexts. In order to understand and respond appropriately to the problem of poor hypertension control in our health district, we conducted a study aimed at determining the extent of blood pressure (BP) control and the factors that influence BP control in the district hospital. It was hoped that the findings of this study will assist healthcare providers to target patients in need of specific interventions to optimize their BP control in ours or similar contexts.

\section{Methods}

\section{Design and study setting}

This was a cross sectional study conducted at a 260 bedded peri-urban district hospital in Sedibeng health district, south of Johannesburg. This hospital receives patients referred from three $\mathrm{CHCs}$ and eleven primary health care (PHC) clinics within the Emfuleni municipal area of Sedibeng district. At the time of the study, 30 doctors (Full and part-time) attend to an estimated 350 patients daily, of whom 100 adults were attended at the outpatient department during normal working hours.

\section{Samples, Sampling method and recruitment}

A "Rule of 10" [13] was used; i.e. about 10 subjects were deemed an adequate sample per factor considered to influence blood pressure control. Since 23 factors were considered, the estimated sample size was 230 hypertensive patients. In order to compensate for the possibility of incomplete data the sample size was rounded up to 250 .All consenting adult hypertensive patients, who had been followed up for at least three months and who had visited the outpatient department at least twice after the diagnosis of hypertension, were consecutively selected into the study. Those who were severely ill, had difficulty communicating and those with stroke were excluded. Selection continued until the required sample size was attained. 
At clinic visits, vital signs of hypertensive patients are normally assessed and recorded in the medical records by nurse assistants. After this step, patients who met the inclusion criteria were informed about the research study and consent was obtained. An orange sticker was affixed on their files to prevent double enrolment. Selected patients were sent to a pre-identified room for clinical assessment, treatment and completion of the questionnaire. Literate patients completed the questionnaires while illiterates were assisted by the researcher and a trained nurse. After this, patients went to the pharmacy for dispensing of medications where medical records with orange stickers were kept aside for record review by the first researcher.

\section{Data collection tool and methods of data collection}

Data collection was conducted using a questionnaire developed de novo based on literature review and which was subjected to peer-review by two senior colleagues. The questionnaire collected information on patients' socio-demography, anthropometric measures, clinical co-morbidities, the details, adherence to and side-effects of treatments. Other information included: discussion of patient's condition and treatments, prescriptions and adherence to lifestyle changes. Rapid record review by the researcher collected information on: whether drugs dosage and combinations were in accordance with the South African or JNC-VII hypertension guidelines, $[14,15]$ whether healthcare providers adequately initiated or intensified management actions as required and whether overall management was in accordance with existing South African hypertension guidelines.

\section{Data analysis}

Data was captured from the questionnaire unto Microsoft excel template which was imported into Epi-Info version 3.5.1 (2008). Descriptive statistics characterized patients' socio-demographic profiles. The proportion of patients with controlled BP (defined according to guidelines), the prevalence of both clinical 
co-morbidity and selected factors were also determined. Group comparisons were done using Chi-square test for categorical data or Fisher's exact test (where data cells were less than five) and t-test for continuous data. Multivariate regression analysis was used to determine factors which are independently associated with uncontrolled blood pressures. P values less than 0.05 were considered statistically significant.

\section{Ethics}

Informed written consent was obtained from patients before enrolment into the study. All information collected from participants was kept confidential with only the researchers having access to them. All identifying data were coded and not identifiable to any patient. Ethics clearance was obtained from the Medical Research and Ethics committee at the University of Pretoria, South Africa. Permission to conduct the study was also obtained from the executive management of Kopanong hospital.

\section{Results}

A total of 251 patients completed the questionnaires of whom the majority were females $(63.8 \%)$ and Blacks (64.5\%). Most participants were unemployed, with a mean age of 60.1 years (range: 35 to 90 years). Only $24.3 \%$ (61) of participants reported smoking cigarette while $27.9 \%(70)$ took alcohol regularly. Other socio-demographic characteristics are as shown in table 1.

BP control was achieved in $31.5 \%$ and $16.7 \%$ of participants at the current and last clinic-visits respectively. Most reported co-morbidities had cardiovascular implications and included: Obesity (39.0\%), Diabetes mellitus (29.5\%), History of myocardial Infarction (18.3\%), heart failure (15.1\%) and gout (10.0\%). Other reported non-cardiovascular co-morbidities included: HIV infection (14.3\%) and arthritis (13.6\%). 
Table 1: Participants socio-demographic characteristics

\begin{tabular}{|l|l|l|}
\hline Characteristics & $\%$ (n) & Mean (SD) \\
\hline Age (Years) & & $\begin{array}{l}60.1+11.0 \\
\text { Range: } 35-90\end{array}$ \\
\hline Sex & & \\
\hline Female & $63.8(160)$ & \\
\hline Male & $36.2(91)$ & \\
\hline Race & & \\
\hline Blacks & $64.5(162)$ & \\
\hline Whites & $21.5(54)$ & \\
\hline Indian & $6.8(17)$ & \\
\hline Coloured & $7.2(18)$ & \\
\hline Marital status & & \\
\hline Married & $51(128)$ & \\
\hline Single & $13.1(33)$ & \\
\hline Co-habit & $6.0(15)$ & \\
\hline Divorced / Widowed & $29.9(75)$ & \\
\hline Cigarette smoking & & \\
\hline Yes & $24.3(61)$ & \\
\hline No & $75.7(190)$ & \\
\hline Regular alcohol intake & & \\
\hline Yes & $27.9(70)$ & \\
\hline No & $72.1(181)$ & \\
\hline Educational level & & \\
\hline Never attended school & $15.5(39)$ & \\
\hline Primary school & $50.2(126)$ & \\
\hline Secondary and beyond & $34.3(86)$ & \\
\hline Distance between residence and hospital & & \\
\hline & $30.3(76)$ & \\
\hline$<10$ Km & $64.5(162)$ & \\
\hline \multicolumn{1}{|c|}{ 10 Km } & $5.2(13)$ & \\
\hline
\end{tabular}


Table 2: Participants' clinical and treatment characteristics

\begin{tabular}{|l|l|}
\hline Variables & $\%(\mathbf{n})$ \\
\hline Current BP controlled & \\
\hline Yes & $31.5(79)$ \\
\hline No & $68.5(172)$ \\
\hline Last Visit BP controlled & \\
\hline Yes & $16.7(42)$ \\
\hline No & $83.3(209)$ \\
\hline Clinical co-morbidities & \\
\hline Obesity & $39.0(98)$ \\
\hline Diabetes & $29.5(74)$ \\
\hline Myocardial infarction & $18.3(46)$ \\
\hline Heart failure & $15.1(38)$ \\
\hline On HIV treatment & $14.3(36)$ \\
\hline Arthritis & $13.6(34)$ \\
\hline Gout & $10.0(25)$ \\
\hline Treatment duration & \\
\hline $3-11$ months & $13.5(34)$ \\
\hline 1 year - 5 years & $25.9(65)$ \\
\hline$>5$ years & $60.6(152)$ \\
\hline Number of antihypertensive drugs & \\
\hline Two & $6.4(16)$ \\
\hline Three & $19.2(48)$ \\
\hline$>$ Three & $74.4(186)$ \\
\hline Times per week missed treatment per week & \\
\hline Never & $86.5(217)$ \\
\hline $1-3$ doses & $12.4(31)$ \\
\hline$>3$ doses & $1.2(3)$ \\
\hline Treatment in accordance to guideline (dosage and combination) & \\
\hline Yes & $77.7(195)$ \\
\hline No & $22.3(56)$ \\
\hline Lifestyle modification intensified by doctor when necessary & \\
\hline & \\
\hline
\end{tabular}




\begin{tabular}{|l|l|}
\hline Adequate & $61.3(154)$ \\
\hline Not adequate & $38.7(97)$ \\
\hline Treatment explained to patient & \\
\hline Yes & $96.8(243)$ \\
\hline No & $3.2(8)$ \\
\hline Medication side-effects experienced by participants & \\
\hline Dizzy & $7.6(19)$ \\
\hline Weakness & $3.6(9)$ \\
\hline Swelling & $3.2(8)$ \\
\hline Headache & $3.2(8)$ \\
\hline Cough & $1.6(4)$ \\
\hline
\end{tabular}

Most participants $(60.6 \%)$ had been on treatment for more than 5 years and $77.7 \%(195)$ were on adequate treatment according to guideline (dosage and combinations). The majority of participants (93.6\%) were on 3 or more drugs and adhered to treatment protocols, with $86.5 \%$ reporting that they had never missed their medications in the last week. Other clinical and treatment characteristics are shown in table 2.

On bivariate analyses, participants who were divorced / widowed were significantly more likely than married participants to have uncontrolled hypertension [OR $=3.2 ; 95 \% \mathrm{Cl}(1.58-6.33) ; \mathrm{P}=0.001]$. Similarly, obese participants (defined as having $\mathrm{BM}>30 \mathrm{Kg} / \mathrm{M}^{2}$ ) were twice as likely as those who were not to have uncontrolled hypertension $[\mathrm{OR}=2.1 ; 95 \% \mathrm{Cl}(1.15-3.65) ; \mathrm{P}=0.02]$. Compared to those who reported never missing their treatments, those who missed 1-3 doses in the previous week had increased odds of uncontrolled hypertension [OR $=3.57 ; 95 \% \mathrm{Cl}(1.20-10.57) ; \mathrm{P}=0.02]$. However, compared to no formal education, having secondary education or more was associated with lower odds of uncontrolled hypertension $[\mathrm{OR}=0.36 ; 95 \% \mathrm{Cl}(0.15-0.87) ; \mathrm{P}=0.02]$.

The results of the final multivariate regression analysis are shown in table 3 and indicate that of all the socio-demographic and clinical variables, only a past history of myocardial infarction was protective against 
Table 3: Final multivariate regression analysis of predictors of uncontrolled blood pressure

\begin{tabular}{|l|l|l|}
\hline Explanatory variables & Odds ratio (95\%Cl) & P values \\
\hline Marital status & & \\
\hline Married & 1 & \\
\hline Single & $1.49(0.57-3.90)$ & \\
\hline Co-habit & $0.92(0.20-4.15)$ & \\
\hline Divorced/Widowed & $3.1(1.34-6.99)$ & $p=0.01$ \\
\hline & & \\
\hline History of myocardial infarction & & \\
\hline No & 1 & \\
\hline Yes & $0.41(0.18-0.95)$ & $P=0.04$ \\
\hline & & \\
\hline
\end{tabular}

Number of observations $=247$

$\operatorname{LR} \operatorname{chi}^{2}(25) \quad=56.22$

Prob $>$ chi $^{2} \quad=0.0003$

Log likelihood $=-125.93063 \quad$ Pseudo $\mathrm{R}^{2} \quad=0.1825$

uncontrolled hypertension [OR $=0.41 ; 95 \% \mathrm{Cl}(0.18-0.95) ; \mathrm{P}=0.04]$ and being divorced / widowed predicted having uncontrolled hypertension [OR $=3.1 ; 95 \mathrm{Cl}(1.33-6.99) ; \mathrm{P}=0.01]$.

\section{Discussion}

The findings of this study reiterate that most patients with hypertension are not well controlled and in addition suggest that social support network and an experience of life-threatening CVD event may play significant roles in the achievement of optimal BP control.

That hypertension control is suboptimal in the majority of participants is a confirmation of the findings of previous reports in South Africa and elsewhere, [1, 16] and has serious clinical and public health implications. Uncontrolled hypertension predisposes individual patients to significant risk of CVD and within a context of high prevalence, [12] imposes a high public health burden of CVD on the health system. However, dealing with these impositions is a tall order for the South African health system that is already 
inundated by the burden of HIVIAIDS, TB and other infectious diseases, maternal and peri-natal disorders, trauma and violence. [17]

The majority of participants in this study were blacks and females, in agreement with reports that women seek and utilized public healthcare services more frequently than men in South Africa. [4] This finding has clinical implications in that women have a greater lifetime risk of stroke and stroke mortality [18] and black South African have a higher prevalence, more severe forms, more complications and poorer BP control compared to other racial groups. [16] Therefore, interventions for hypertension in South Africa need to target this population subset, both to screen and to intensify treatment.

Table 2 shows that most co-morbidity found in this study are independent CV risk factors and highlights the fact that most patients with hypertension have other CV risks. Reducing the risk of CVD should therefore involve more than hypertension control. Co-morbidities such as obesity and diabetes which are prevalent in South Africa $[9,10,19]$ and are associated with lower odds of BP control [12] should be screened for and managed in addition to controlling hypertension, in order to reduce adverse CV outcomes,.

The vast majority of participants (93.6\%) in this study were on three or more antihypertensive drugs and most $(60.6 \%)$ had been used for longer than 5 years, suggesting that BP control was never good and treatment regimes needed overhaul. The retention of such patients in a district hospital highlights healthcare professionals' apathy and contradicts evidence-based hypertension guidelines recommendation that such patients be managed by physicians and subspecialists at secondary or tertiary levels of care. [14] This apathy needs to be addressed urgently as it exposes patients to complications that could be prevented, were early referral considered.

This study employed a cross sectional design and therefore cannot infer causation. Given the potential for incomplete data during record review and the use of self-report, information bias could not have been 
completely eliminated. The selection of patients who presented during the working hours predisposes the study to selection bias by excluding those presenting after-hours. However, patients presenting afterhours are emergencies and would have not met the inclusion criteria. The measurement of BP by different nurses could have led to inter-rater variations and subsequent misclassifications. However, BP measurements were standardized through training of nurses on the use of the South African hypertension guideline BP measurement procedures [19] and using the same calibrated electronic BP machines.

In conclusion, this study reiterates the highly prevalent suboptimal BP control among patients with hypertension. Although findings suggest a predictive relationship between being married, a past history of myocardial infarction and BP control, the use of a sample that was not nationally representative and the presence of potential confounders makes it difficult to meaningfully suggest explanations for these relationships. Larger and better designed studies are therefore needed to examine and explain the relationships between these factors and $\mathrm{BP}$ control.

Competing interest: None.

Funding: This research received no specific grant from any funding agency in the public, commercial, or not-for-profit sectors.

\section{Authors' contributions}

MM was involved in the conception, design, data collection, analysis and interpretation of the results, revising of the manuscript and gave final approval for the final version to be published.

$\mathrm{OB}$ was involved in the conception, design, data interpretation of results, supervision, drafting of the manuscript, revising the manuscript, and gave final approval for the final version to be published. 
MC was involved in the conception, design, data interpretation of results, supervision, revising the manuscript, and gave final approval for the final version to be published.

\section{Authors' information}

MM is a Specialist Family physician in Private practice, Vereeniging, Gauteng, South Africa and at the time of the study was a postgraduate student at the Department of Family Medicine, University of Pretoria, South Africa.

OB is Head of Clinical Unit (DCST) and Senior Lecturer at the Department of Family Medicine, University of the Witwatersrand, South Africa.

MC is Head of Clinical Unit and Senior Lecturer at the Department of Family Medicine, University of Pretoria, South Africa

Acknowledgement: Prof. PJ Becker and Ms Lieketseng for assistance with statistical analysis.

\section{References}

1. World Health Organization. A global brief on hypertension. Silent killer, global public health crisis. WHO 2013; Geneva, Switzerland. Available online at http://apps.who.int/bitstream/10665/790591/1/WHO_DCO_WHD_2013.2_eng.pdf?ua=1 Accessed $2014 / 04 / 12$

2. Peltzer K, Phaswana-Mafuya N. Hypertension and associated factors in older adults in South Africa. Cardiovasc J Afr 2013;24:67-71 PubMed .

3. Gaziano T, Reddy KS, Paccaud F, Horton S. Cardiovascular disease In: Jamison D et al, eds. Disease control priorities in developing countries, $2^{\text {nd }}$ Ed. New York: Oxford University press and the World Bank, 2006: 645-62. 
4. Department of Health, Medical Research Council, OrcMacro.2007. South Africa Demography and Health Survey 2003. Pretoria: Department of Health. http://www.mrc.ac.za/bod/sadhs2003part1.pdf Accessed 2011/03/09

5. Ker JA. Essential hypertension. CME;2006:176-182

6. Trilling JS, Froom J. The urgent need to improve hypertension care. Arc Fam Med 2000;9:794801 PubMed.

7. Agyemang C, Bruijnzeels MA, Owusu-Dabo E. Factors associated with hypertension awareness, treatment, and control in Ghana, West Africa. J Hum Hypertens. 2006;20:67-71.

8. Seedat YK. Hypertension in developing nations in sub-Saharan Africa. J Hum Hypertens 2000;14:739-47 PubMed

9. Peer N, et al. Target organ damage in black South African patients with hypertension. J Clin Hypertens 2006; 8: A174.

10. Peer N, Steyn K, Lombard C, Gwebushe N and Levitt N. A high burden of hypertension in the urban black population of Cape Town: The Cardiovascular Risk in Black South Africans (CRIBSA) Study. PloS One 2013;8:e78567.doi: 10.1371/journal.pone.0078567. Accessed 2014/04/12

11. Onwukwe SC, Omole OB. Drug therapy, life style modification and blood pressure control in a primary care facility, south of Johannesburg: an audit of hypertension management. S Afr Fam Pract J 2012;54:156-161 PubMed

12. Lloyd-Sherlock P, Beard J, Minicuci N, Ebrahim S, Chatterji S. Hypertension among older adults in low- and middle-income countries: prevalence, awareness and control. Int J Epidemiol. 2014;43:116-28.

13. Garson D. Factor Analysis. Sursa: http://www2.chass.ncsu.edu/garson/pa765/factor.htm. Accessed $\underline{2014 / 04 / 05}$ 
14. Seedat YK, Croasdale MA, Milne FJ, Opie LH, Pinkney-Atkinson VJ, Rayner BL et al. South African hypertension guideline 2006. S Afr Med J 2006;96:337-62 PubMed .

15. Seventh Report of the Joint National Committee on Prevention, Detection, Evaluation and Treatment of high blood pressure. The JNC-VII Report JAMA 2003; 289: 2560-72 PubMed .

16. Rayner B. Hypertension: Detection and management in South Africa. Nephron Clin Pract 2010;116:c269-c273.

17. Mayosi BM, Flisher AJ, Lalloo UG, Sitas F, Tollman SM, Bradshaw D. The burden of noncommunicable diseases in South Africa. Lancet 2009;374:934-47 PubMed

18. Zhou G, Nie S, Dai L, Wang X, Fan W. Sex differences in stroke case fatality: a meta-analysis. Acta Neuro Scand. 2013;128:1-8 PubMed

19. Mkhonto SS, Labadarios D, Mabaso ML. Association of body weight and physical activity with blood pressure in a rural population in the Dikgale village of Limpopo Province in South Africa. BMC Res Notes 2012; 5:118. PubMed doi:10.1186/1756-0500-5-118. Accessed 2104/04/12. 